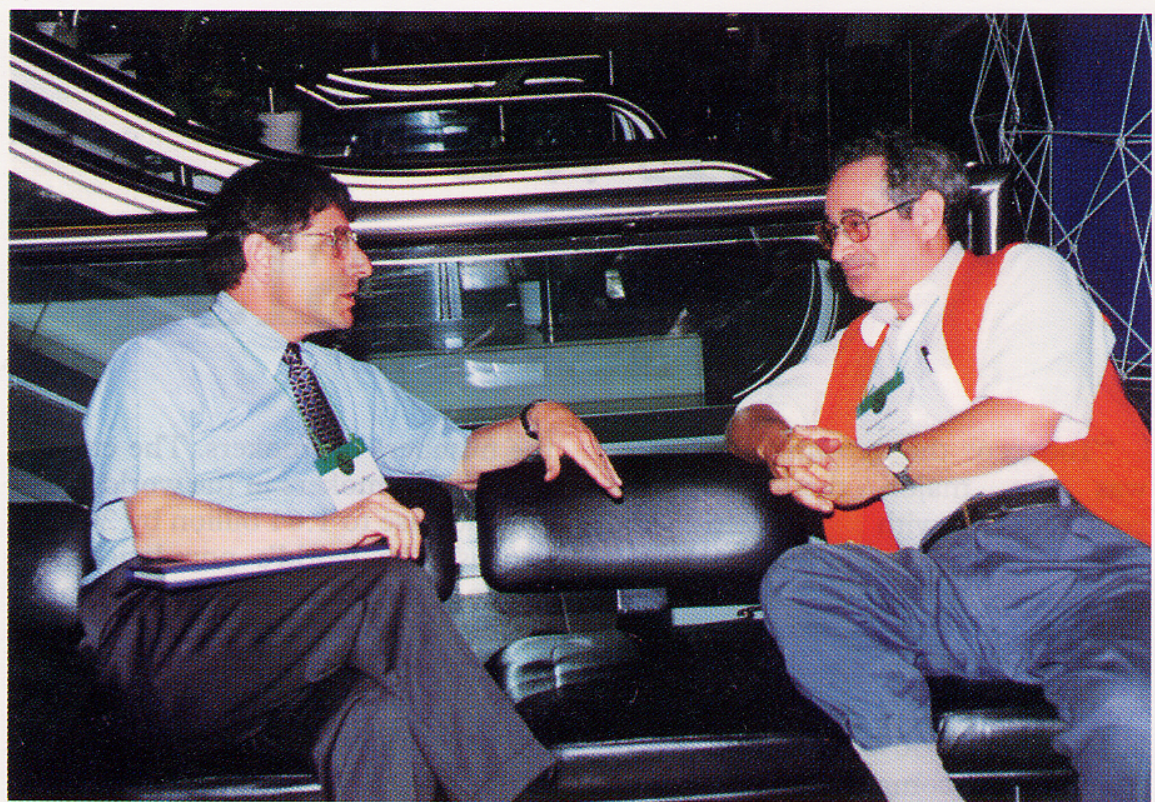

American delegates Matt Myers (left) and Stan Glantz, in relaxing conversation at the conference, before engaging in a heated debate at a well-attended session on the United States tobacco industry settlement agreement. [Photo credit: David Mannino]

litigation, legislation, tobacco promotion, world trade and smuggling, addiction and cessation, young people, school and families, passive smoking, occupational health, tobacco and religion, and the effect of tobacco on economies. The role of health professionals, the United Nations and governments in tobacco control also came under scrutiny.

Arguments were put forward for government regulation on tobacco manufacturing standards, the development of global and regional taxation and regulatory measures, and an international crackdown on smuggling and the corruption that accompanies it. Health professionals were told they must be better role models, and some speakers advocated wider use of nicotine replacement therapies. Sport was urged to boycott tobacco sponsorship. The economic message that emerged from the conference was that tobacco control was good not only for health, but also for a country's economy.

Emphasis was placed on different methods of cessation, for if efforts concentrate only on preventing children from smoking, there will be no reduction in the 200 million smoking-related deaths expected to occur before 2025 in people who already smoke.

One controversial decision was to invite a tobacco industry scientist who stated in his abstract that he believes "the data do not demonstrate that ETS [environmental tobacco smoke] exposure increases the risk of lung cancer or heart disease". The reason behind the decision to invite him was to allow his findings to be scrutinised in an open session by his peers, four of whom duly provided a robust and highly critical analysis of his case.

Other interesting topics in the conference included religion and tobacco (with Buddhist, Christian, and Islamic representatives examining their beliefs and practices in relation to tobacco), the environmental aspects of tobacco (cutting down trees to cure tobacco; fires caused by careless smoking; passive smoking; rubbish/garbage caused by the billions of discarded cigarettes, matches, and packets each day), and tobacco advertising on the internet.

One novelty was the "How-to" workshops-how to lobby, fund-raise, prepare and present papers, introduce tobacco into the medical curriculum, free sports from tobacco, and how to network electronically. In relation to the last topic, the conference had two internet sites (see page 362 of this issue), and the International Union Against Cancer's (UICC's) GLOBALink computers were in use by delegates throughout the conference.

Even before the conference, three workshops on abstract preparation and paper presentation skills were held around Asia. Delegates were also offered expert help in the presentation of their papers before their sessions, and an on-the-spot slide-making machine was available.

An "empty" session had been held until three weeks before the conference for any last-minute issue of importance, and there was no doubt that this had to be the proposed United States settlement with the tobacco companies. The Resolutions Committee received more submis- sions on this topic than on any other. These submissions differed quite considerably on specific recommendations, but there was, however, a broad 음 consensus on the principles as they $\delta$ should apply to all countries, and $\underset{\equiv}{\vec{I}}$ these were reflected in the resolutions, 을 which apply not only to the United $\overrightarrow{\vec{A}}$ States, but also to the UK, Japan, $\frac{\text { ? }}{9}$ Indonesia, and other large exporting 등 countries.

It was hoped that all delegates would be able to draw on these princi- $\frac{2}{2}$ ples for their own campaigns, for $\infty$ example, with regard to the current $\overrightarrow{0}$ United States settlement. In addition, $\overrightarrow{\vec{\omega}}$ letters were circulated for delegates to $\stackrel{\omega}{\omega}$ sign, such as a letter addressed to $\vec{\cap}$ American President Bill Clinton.

The conference received unparal- $\overrightarrow{\text { i }}$ leled global media coverage through $\sigma$ the Press Office, which was supported 을 by the World Health Organisation (WHO). Overwhelmingly, delegates expressed their appreciation on the $\overparen{\Phi}$ venue, programme content, and many 3 other aspects of the conference. It was organised by the Chinese Association $\vec{\theta}$ on Smoking and Health and the Chinese Medical Association under the auspices of several international bodies, including the WHO, the United Nations Conference on Trade and Development (UNCTAD), the 요 United Nations Children's Fund $\cong$ (UNICEF), the UICC, and the 을 American Cancer Society.

$$
\begin{array}{r}
\text { JUDITH MACKAY } \\
\text { Asian Consultancy on Tobacco Control, } \\
\text { Hong Kong, China; } \\
\text { email: jmackay@hk. super.net } \\
\text { Oे } \\
\text { fudith Mackay is senior advisor to the Chinese } \\
\text { Association on Smoking and Health, and was } \\
\text { senior advisor to the organising committee and } \\
\text { vice-chair of the scientific committee of the 10th } \\
\text { World Conference on Tobacco or Health. -ED } \\
\text { Beauty Or the beast }
\end{array}
$$

\section{Beauty or the beast}

If one delegate stood out more than most in Beijing, it was surely a tall, strikingly beautiful young woman from Sweden who was often to be seen striding purposefully between $\mathrm{O}$ sessions, particularly those dealing $\underset{\omega}{N}$ with tobacco smoking among children and women. This was Annika Duckmark, who was crowned Miss $\mathbb{\complement}$ Sweden 1996, the second holder of the title since it became a significant $\frac{7}{0}$ part of Sweden's tobacco education $\stackrel{\overparen{D}}{\overparen{D}}$ programme. The idea of making Miss $\frac{\curvearrowright}{\mathbb{D}}$ Sweden smoke-free came up in 1995 when Annika's predecessor, Petra Hultgren, took the title while still a o smoker. She was quick to realise that smoking would be detrimental to her 윽 image, and she contacted Margaretha Haglund of Sweden's National Institute of Public Health, for advice. 